\title{
The effectiveness of oral health education and toothbrush training in decreasing plaque index score among Elementary Students in Jakarta
}

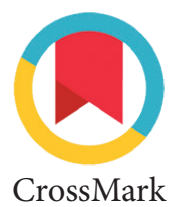

\author{
Helwiah Umniyati, ${ }^{*}$ Benanziski Miegasivia, Muhamad Zakki
}

\section{Abstract}

Objective: To know the effectiveness of dental health education on decreasing plaque index score and increasing salivary $\mathrm{pH}$ among elementary school children in SD 01 Pagi Kampung Rawa, Central Jakarta.

Material and Methods: Quasi experimental study with pre and post-test design among 93 students which divided into four groups, group 1: control group, group 2: education group without tooth brushing training, group 3: education with 1 times tooth brushing training and group 4: education group with 4 times tooth brushing training. The plaque index assessed by the Personal Hygiene Performance Index (PHP) method. Data analysis performed with paired samples
T-Test and One-Way ANOVA using SPSS 23.

Results: At baseline there were no significant difference on plaque score among four groups ( $p>0.05$ ). There significant decreasing in plaque score after intervention in group 2, 3 and $4(p<0.005)$, but not in group control. When analyzing plaque score after intervention among four groups, there was no significant difference on plaque score between group 1 (control) and group 2. There were significant difference on plaque score between group 1 and group 3 or 4 and between group 2 and group 4.

Conclusion: Dental health education with tooth brushing training is an effective way to reduce the plaque index score.
Department of Dental of Public Health, Faculty of Dentistry, YARSI University, Jakarta, Indonesia
*Correspondence to: Helwiah Umniyati, Department of Dental of Public Health, Faculty of Dentistry, YARSI University, Jakarta, Indonesia

helwiah@yarsi.ac.id; helwiah@gmail.com hard tissue. ${ }^{2}$ Based on the results of Riskesdas 2018 almost all residents brushed their teeth every day $(94.7 \%)$, but only $2.8 \%$ of them brush their teeth in the correct time which were in the morning after breakfast and at night before going to bed. DKI Jakarta province had the highest proportion of people who brushed their teeth every day (97.5\%), but only $2.7 \%$ of the population brushed their teeth in correct time.

Mechanical plaque removal, if performed

Keywords: Oral health education, Plaque Index score, Tooth brushing training Cite this Article: Umniyati H, Miegasivia B, Zakki M. 2020. The effectiveness of oral health education and toothbrush training in decreasing plaque index score among Elementary Students in Jakarta. Journal of Dentomaxillofacial Science 5(3): 168-172. D0l: 10.15562/jdmfs.v5i3.1102

\section{Introduction}

Dental caries is the most common chronic disease among all oral diseases. ${ }^{1}$ The prevalence of dental caries in Indonesia based on Basic Health Research Survey 2018 (RISKESDAS 2018) was 88.8\% and the prevalence among children aged 5-9 years and 10-14 years were as high as $92.6 \%$ and $73.4 \%$. Dental caries are generally caused by poor oral hygiene, resulting in the accumulation of plaque containing various kinds of bacteria. ${ }^{1}$ Plaque is a thin layer, colorless, contains a collection of bacteria, adheres to the surface of the teeth and always forms in the mouth and if mix with the sugar in the food to form an acid will trigger the demineralization of tooth effectively, can be the most effective method for maintaining good oral hygiene, reducing tooth decay, and improving gingival health., Various methods are used to maintain oral hygiene, the most common of which is tooth brushing. ${ }^{4}$ Toothbrushing is an effective way to remove plaque, prevent gingivitis and dental caries. ${ }^{5}$ However, the compliance to practice regular brushing in the right time as the prevention of dental caries was still poor. ${ }^{6}$ Effective plaque removal depends not only on the type of toothbrush, but also on the correct brushing technique. ${ }^{7}$ Previous research has proven that the effective tooth brushing procedure in removing plaque was Bass modification technique, for two minutes, twice a day i.e. in the morning after breakfast, and at night before bed. ${ }^{8,9}$ Tooth brushing also affects salivary acidity. According to a research conducted by Ligtenberg et al. $^{10}$ there was an increase in $\mathrm{pH}$ value of saliva after brushing the teeth, indicating that brushing teeth triggers changes in salivary $\mathrm{pH} .{ }^{10}$

Oral health education is all effort or activity to influence someone to behave well for healthy teeth and mouth, as well as to increase public awareness of oral health and to provide guidelines to maintain healthy teeth and mouth. ${ }^{11}$ Primary school 
very crucial age in growth and physical development of children because at this time children begin to develop habits that usually tend to persist into adulthood. In this age, oral health education is very important element in school health program for practicing a child's motor skills, including brushing teeth. ${ }^{12}$

Guidelines for tooth brushing should be provided to children continuously until their proper habits of brushing has been embedded in their daily lives.

${ }^{13}$ Research conducted by Wambier et al. ${ }^{14}$ showed that manual tooth brushing was performed repeatedly more effective in lowering the plaque index in children. ${ }^{14}$ Another research conducted by Naidu et al. ${ }^{15}$ told that dental health education with regular practice of tooth brushing in children is also proven to improve plaque index. ${ }^{15}$ The objective of this study was to know the effectiveness of dental and oral health education and training in improving the plaque index score.

\section{Material and Methods}

A quasi-experimental study was conducted in Public Elementary School "SD N Kampung Rawa 01 Pagi" in Central Jakarta from November-December 2017 using a pretest posttest design. There were 93 elementary school children in grades IV

Table 1 Distribution of subject characteristics

\begin{tabular}{|c|c|c|c|c|c|}
\hline \multirow{2}{*}{ Subject Characteristics } & \multicolumn{4}{|c|}{$n(\%)$} & \multirow{2}{*}{$\begin{array}{c}p \\
\text { Value }\end{array}$} \\
\hline & 1 & 2 & 3 & 4 & \\
\hline \multicolumn{6}{|l|}{ Gender } \\
\hline Male & $9(40.9)$ & $14(56)$ & $8(32)$ & $11(52.4)$ & \multirow{2}{*}{0.31} \\
\hline Female & $13(59.1)$ & $11(44)$ & $17(68)$ & $10(47.6)$ & \\
\hline \multicolumn{6}{|l|}{ Age } \\
\hline 9 years & $11(50)$ & $13(52)$ & $2(8)$ & $0(0)$ & \multirow{3}{*}{0.00} \\
\hline 10 years & $7(31.8)$ & $12(48)$ & $12(48)$ & $8(38.1)$ & \\
\hline 11 years & $4(18.2)$ & $0(0)$ & $11(44)$ & 13(61.9) & \\
\hline \multicolumn{6}{|l|}{ Parents' job } \\
\hline Housewife & $14(63.6)$ & $17(68)$ & $16(64)$ & $14(66.7)$ & \multirow{2}{*}{0.98} \\
\hline Entrepreneur/trader & $8(36.4)$ & $8(32)$ & $9(36)$ & $7(33.3)$ & \\
\hline \multicolumn{6}{|l|}{ Parental education } \\
\hline Low (elementary, junior high school) & $8(36.4)$ & $9(36)$ & $7(28)$ & $9(42.9)$ & \multirow{2}{*}{0.77} \\
\hline High (senior high school, college) & $14(63.6)$ & $16(64)$ & $18(72)$ & $12(57.1)$ & \\
\hline \multicolumn{6}{|l|}{ Frequency of brushing teeth } \\
\hline$\geq 2$ times a day & $21(95.5)$ & $22(88)$ & $24(96)$ & $20(95.2)$ & \multirow{2}{*}{0.62} \\
\hline$<2$ times a day & $1(4.5)$ & $3(12)$ & $1(4)$ & $1(4.8)$ & \\
\hline \multicolumn{6}{|l|}{ Toothbrushing time } \\
\hline Right (after breakfast \& before bed) & $3(13.6)$ & $4(16)$ & $4(16)$ & $4(19)$ & \multirow{2}{*}{0.97} \\
\hline False & $19(86.4)$ & $21(84)$ & $21(84)$ & $17(81)$ & \\
\hline \multicolumn{6}{|l|}{ Brushed tooth surface } \\
\hline All surfaces & $18(81.8)$ & $17(68)$ & $19(76)$ & $18(85.7)$ & \multirow{2}{*}{0.50} \\
\hline Not all surfaces & $4(18.2)$ & $8(32)$ & $6(24)$ & $3(14.3)$ & \\
\hline \multicolumn{6}{|l|}{ Visiting dentist } \\
\hline$\leq 6$ month & $4(18.2)$ & $7(28)$ & $8(32)$ & $3(14.3)$ & \multirow{2}{*}{0.45} \\
\hline$>6$ month & $18(81.8)$ & $18(72)$ & $17(68)$ & $18(85.7)$ & \\
\hline \multicolumn{6}{|l|}{ Use of a toothbrush } \\
\hline Together with other family member & $1(4.5)$ & $3(12)$ & $1(4)$ & $1(4.8)$ & \multirow{2}{*}{0.62} \\
\hline Alone & $21(95.5)$ & $22(88)$ & $24(96)$ & $20(95.2)$ & \\
\hline \multicolumn{6}{|l|}{ Frequency of consumption of sweet diets } \\
\hline$\leq 2$ times a day & $16(72.7)$ & $19(76)$ & $18(72)$ & $15(71)$ & \multirow{2}{*}{0.98} \\
\hline$>2$ times a day & $6(27.3)$ & $6(24)$ & $7(28)$ & $6(28.6)$ & \\
\hline
\end{tabular}


Table 2 Comparison of plaque index values before and after intervention (intra group)

\begin{tabular}{lccccc}
\hline \multirow{2}{*}{ Group } & & \multicolumn{3}{c}{ Plaque index score } & \multirow{2}{*}{ P Value* } \\
\cline { 3 - 5 } & $\mathbf{N}$ & Before intervention & After intervention & Difference & \multirow{2}{*}{0.715} \\
1 & 22 & $3.34 \pm 1.09$ & $3.50 \pm 0.78$ & $-0.16 \pm 0.31$ & $<0.005$ \\
2 & 25 & $3.68 \pm 0.88$ & $2.90 \pm 1.06$ & $0.78 \pm 0.18$ & $<0.0005$ \\
3 & 25 & $3.60 \pm 0.63$ & $2.33 \pm 0.70$ & $1.27 \pm 0.07$ & $<0.0005$ \\
4 & 21 & $4.01 \pm 0.74$ & $2.19 \pm 0.50$ & $1.82 \pm 0.24$ & \\
\hline
\end{tabular}

Group 1 control group; Group 2 education; Group 3 education +1 training; Group 4 education +4 training.

Table 3 Comparison of plaque index scores among four groups

\begin{tabular}{|c|c|c|c|c|c|}
\hline \multirow{2}{*}{ Group } & \multirow[b]{2}{*}{$\mathbf{n}$} & \multicolumn{2}{|c|}{ Before intervention } & \multicolumn{2}{|c|}{ After intervention } \\
\hline & & Plaque score & $\mathbf{P}$ & Plaque score & $\mathbf{P}$ \\
\hline 1 & 22 & $3.34 \pm 1.09$ & \multirow{4}{*}{0.127} & $3.50 \pm 0.78$ & \multirow{4}{*}{$<0.0005$} \\
\hline 2 & 25 & $3.68 \pm 0.88$ & & $2.90 \pm 1.06$ & \\
\hline 3 & 25 & $3.60 \pm 0.63$ & & $2.33 \pm 0.70$ & \\
\hline 4 & 21 & $4.01 \pm 0.74$ & & $2.19 \pm 0.50$ & \\
\hline
\end{tabular}

Group 1 control group; Group 2 education; Group 3 education +1 training; Group 4 education +4 training.

Table 4 Post-hoc test results of Plaque Index Scores after intervention

\begin{tabular}{lcccc}
\hline \multicolumn{4}{c}{ Comparison between group } & \\
\cline { 1 - 3 } Group & Plaque score & Group & Plaque score & \multirow{2}{*}{ p Value* } \\
\hline 1 & $3.50 \pm 0.78$ & 2 & $2.90 \pm 1.06$ & 0.102 \\
1 & $3.50 \pm 0.78$ & 3 & $2.33 \pm 0.70$ & $<0.0005$ \\
1 & $3.50 \pm 0.78$ & 4 & $2.19 \pm 0.50$ & $<0.0005$ \\
2 & $2.90 \pm 1.06$ & 3 & $2.33 \pm 0.70$ & 0.049 \\
2 & $2.90 \pm 1.06$ & 4 & $2.19 \pm 0.50$ & 0.021 \\
3 & $2.33 \pm 0.70$ & 4 & $2.19 \pm 0.50$ & 0.528 \\
\hline
\end{tabular}

${ }^{\star}$ Group 1 control group; Group 2 education; Group 3 education +1 training; Group 4 education +4 training.

and $\mathrm{V}$ participated in this study. The subjects in this study were divided into four groups, group 1 was the control group with no intervention given, group 2 was given oral health education counseling, group 3 was given oral health education counseling and training on tooth brushing once, and group 4 was given oral health education counseling and training on tooth brushing as many as four times with frequency once a week. Children from group 3 and 4 were taught to brush their teeth according to Fones technique or circular technique combined with horizontal movement of the occlusal surface, called a scrub brush technique. ${ }^{16}$ We used models, video, and also by live demonstration. In toothbrush training all the students practiced the right way to brush their teeth under supervision. Children was instructed to brush their teeth twice a day for 2 minutes using a groundnut-size fluoride toothpaste. Plaque index was calculated using the Personal Hygiene
Performance Index (PHP) method. This index was developed with the aim of assessing individuals in cleaning debris after being given instructions on brushing by using disclosing solution. ${ }^{16}$ Crown of the tooth was divided into five sub-divisions, namely distal (D), middle third gingival (G), mesial (M), middle third (C), middle third incisal or occlusal $(\mathrm{I} / \mathrm{O})$. The examination was carried out systematically on: Labial surface of the upper right first incisor (11). Labial surface of the lower left first incisor (31). The buccal surface of the right upper first molar (16). The buccal surface of the upper left first molar (26). The lingual surface of the lower left first molar (36). The lingual surface of the lower right first molar (46). The criteria for assessing the level of oral hygiene based on the PHP plaque index were: Very Good=0; Good=0.1-1.7; Medium $=$ 1.8-3.4; $\mathrm{Bad}=3 \cdot 5-5 \cdot{ }^{16,17}$ The data obtained were processed with SPSS 23.0 statistical software. 
Analysis of the data used paired samples T-Test and One-Way ANOVA.

\section{Results}

Comparing each variable among 4 group interventions showed no significant differences in almost all variables except in variable age. It means all four group had the same characteristic.

Table 2 showed the effect of the intervention on the mean plaque index scores in each group. The results showed significant decreases in the mean scores of the plaque after intervention in group 2, group 3, and group 4, while in group 1 (control group) there was an increase on mean plaque index score $(p>0.05)$. From all groups, group 4 had the largest decrease in plaque index score compare to other groups.

Table 3 showed the test result of the comparison the average plaque index scores among four groups before intervention and after intervention. There was no significant difference on mean plaque index scores before intervention among four groups study with $\mathrm{p}$-value $=0.127(\mathrm{p}>0.05)$. After intervention, there were significant differences on means of plaque score index among four group interventions $(\mathrm{p}=0.000)$.

Table 4 showed the comparison of mean plaque indexscores between groups after intervention. There were significant differences on means of plaque score between group 1 (control group) and group 3 or group 4 with p-value $=0.000$. We found also significant difference of mean plaque scores between group 2 and 4 with $\mathrm{p}$ value $=0.021$.

\section{Discussion}

In this study we used quasi experimental design.We found that all variables did not show statistically significant differences, except on variable agebecause the students were not from the same grades. This was the limitation of this study, we used two classes of grade 4 and two classes of grade 5 students. Other limitation was a small number of samples, we just got 93 students for 4 groups interventions.

Analysis was conducted to see the differences in average plaque index scores before and after the intervention. In control group (group 1), there was no decrease in plaque index score, there was even an increase in the score.In intervention groups (group 2, group 3 and group 4), there were significant changes in plaque index scores. The results were in line with various previous studies ${ }^{18-26}$ that the average plaque index score before and after the intervention decreased significantly. It showed that the provision of education using the demonstration succeeded in effectively conveying messages about how to brush teeth and to maintain oral health to elementary school students. The use of audio visual media attracts the attention of elementary school students so that students pay attention to the message conveyed when providing education, and the use of large dental phantom helps to explain effectively how to brush teeth properly. ${ }^{15}$ The highest plaque score reduction was in group 4 where in this group students were taught and monitored brushing their teeth four times once a week.

Comparison of the average plaque index scores showed no significant difference between the control group (group 1) and the group that was only given education (group 2) although the mean plaque index score was lower in group 2. This result may be due to the insufficient number of samples in each intervention group or it may be because the provision of education alone without practice was less effective in reduction plaque scores. Educational intervention alone without practicing was poorly understood by children. Children education group is less effective in forming good and correct tooth brushing habits. Hebbal et al. ${ }^{18}$ stated that the lack of improvement in oral hygiene occurs because the subjects do not practice what they have learned through education. Darwita et al. ${ }^{11}$ stated that practice or trial is one of the learning processes that need to be done in order to get maximal results. ${ }^{11,15}$

There were significant differences of the average plaque index score between group 1- group 3; group1-group 4; group2-group 3 and group2group $4(p<0.05)$. These results indicated that education with brushing training wasan effective way in decreasing plaque index scores, as stated by Wambier et al. $^{14}$ that the counseling program accompanied by training would be more effective in reducing the average plaque index score. This result was also supported by Colaizzi et al. ${ }^{27}$ stating that by giving opportunity to learn accompanied by practice would be more supportive in forming and maintaining new abilities. ${ }^{27}$

However, when comparing between group 3 and group 4, this study showed no significant difference in reducing plaque index scores. This maybe that the students understood well the practice of brushing even with just one practice so we do not need many times to teach them. These results were not in line with a research conducted by Wambier et al. ${ }^{14}$ stating that repeated training would be more effective in reducing the plaque index scores as compared to a training conducted only once. This different result can be understood because preschool children where the skills of these aged were still low, so repetition several times to learn new habits was needed, whereas in our study the subjects was elementary school-age children, most 
of them was aged 10 years and older so that the subjects already had better skills. ${ }^{14}$

\section{Conclusion}

The study that improving plaque score index by education and training in toothbrushing provided to primary school students was more effective as compared to only providing education. Repeated brushing education and training had the same effectiveness as compared to once brushing education and training. With these positive findings, it is recommended that similar programs be supported and implemented with a larger sample size to determine the long-term effect of such programs and to improve the poor oral health situation among school children.

\section{Acknowledgment}

The authors would like to thank to the principal of public elementary school "SDN Kampung Rawa 01 Pagi" and the teachers for assisting the implementation of this research.

\section{Conflict of Interest}

The authors report no conflict of interest.

\section{References}

1. Animireddy D, Reddy BV, Vallala P, et al. Evaluation of $\mathrm{pH}$, buffering capacity, viscosity and flow rate levels of saliva in caries-free, minimal caries and nursing caries children: An in vivo study. Contemp Clin Dent 2014;5: 324.

2. Shetty C, Hegde MN, Devadiga D. Correlation between dental caries with salivary flow, $\mathrm{pH}$, and buffering capacity in adult south Indian population: An in-vivo study. Int J Res Ayurveda Pharm 2013;4: 219-223.

3. Lindhe J, Axelsson P, Tollskog G. Effect of proper oral hygiene on gingivitis and dental caries in Swedish schoolchildren. Community Dent Oral Epidemiol 1975;3: 150-155.

4. Dale JW. Toothbrushing frequency and its relationship to dental caries and periodontal disease. Aust Dent J 1969;14: 120-123.

5. Tucker GJ, Andlaw RJ, Burchell CK. The relationship between oral hygiene and dental caries incidence in 11year-old children. A 3-year study. Br Dent J 1976;141: 75-79.

6. Ainamo J. Current basis for the prevention of dental caries. J Indian Dent Assoc 1976;48: 117-124.

7. Saxer UP, Yankell SL. Impact of improved toothbrushes on dental diseases. I. Quintessence Int 1997;28: 513-525.

8. Damle SG, Patil A, Jain S, et al. Effectiveness of supervised toothbrushing and oral health education in improving oral hygiene status and practices of urban and rural school children: a comparative study. J Int Soc Prev Community Dent 2014;4: 175-181.

9. Patil S, Patil P, Kashetty M. Effectiveness of different tooth brushing techniques on the removal of dental plaque in 6-8 year old children of Gulbarga. J Int Soc Prev Community Dent 2014;4: 113.
10. Ligtenberg $\mathrm{A}$, Brand $\mathrm{H}$, Bots $\mathrm{C}$, et al. The effect of toothbrushing on secretion rate, $\mathrm{pH}$ and buffering capacity of saliva. Int J Dent Hyg 2006;4: 104-105.

11. Darwita R, Novrinda H, Budiharto P, et al. The effectiveness of the joint toothbrush program on the risk of dental caries in elementary school students. J Indones Med Assoc 2011;61: 204-209. (In Indonesia)

12. Hariyanti N. Overcoming the failure of dental health education in children with a psychological approach. Dentika Dent J 2008;1: 80-84. (In Indonesia)

13. Pullishery F, Shenoy Panchmal G, Shenoy R. Parental attitudes and tooth brushing habits in preschool children in Mangalore, Karnataka: A cross-sectional study. Int J Clin Pediatr Dent 2013;6: 156-160.

14. Wambier LM, Dias G, Bittar P, et al. The influence of tooth brushing supervision on the dental plaque index and toothbrush wear in preschool children. Rev Odontol UNESP 2013;42: 408-413.

15. Naidu J, Nandlal B. Evaluation of the effectiveness of a primary preventive dental health education programme implemented through school teachers for primary school children in Mysore City. J Int Soc Prev Community Dent 2017;7: 82-89.

16. Putri M, Herijulianti E, Nurjannah N. Science of hard tissue disease prevention and dental support tissue. Jakarta: EGC; 2010. (In Indonesia)

17. Podshadley AG, Haley J V. Method for evaluating oral hygiene performance. Public Health Rep 1968;83: 259-265.

18. Hebbal M, Ankola A V, Vadavi D, et al. Evaluation of knowledge and plaque scores in school children before and after health education. Dent Res J (Isfahan) 2011;8: 189-196.

19. Sadana G, Gupta T, Aggrawal N, et al. Evaluation of the impact of oral health education on oral hygiene knowledge and plaque control of school-going children in the City of Amritsar. J Int Soc Prev Community Dent 2017;7: 259-263.

20. Lindhe J, Koch G. The effect of supervised oral hygiene on the gingiva of children. Progression and inhibition of gingivitis. J Periodontal Res 1966;1: 260-267.

21. Agerbaek N, Melsen B, Lind OP, et al. Effect of regular small group instruction per se on oral health status of Danish schoolchildren. Community Dent Oral Epidemiol 1979;7: 17-20.

22. Englander HR. Supervised deplaquing and improved gingival health in a school program. J Periodontol 1979;50: 394-396.

23. Sutcliffe P, Rayner JA, Brown MD. Daily supervised toothbrushing in nursery schools. Br Dent J 1984;157: 201-204.

24. Hartono SW, Lambri SE, van-Palenstein HWH. Effectiveness of primary school-based oral health education in west Java, Indonesia. Int Dent J 2002;52: 137-143.

25. Damle SG, Patil A, Jain S, et al. Effectiveness of supervised toothbrushing and oral health education in improving oral hygiene status and practices of urban and rural school children: A comparative study. J Int Soc Prevent Communit Dent 2014;4: 175-181.

26. Ilyas M, Putri IN. Effect of demonstration method counseling on brushing teeth to the decreasing of plaque value of elementary school students. J Dentomaxillofac Sci 2012;11: 91-95.

27. Colaizzi LR, Tomar SL, Urdegar SM, et al. Does the structure of dental hygiene instruction impact plaque control in primary school students /?. J Dent Hyg 2015;89: 180-189.

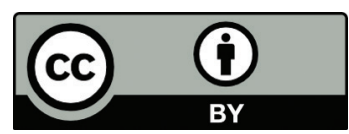

This work is licensed under a Creative Commons Attribution 